\title{
Uma Concepção Popular Sobre a Esquistossomose Mansônica: Os Modos de Transmissão e Prevenção na Perspectiva de Gênero'
}

\author{
A Popular Concept of Schistosomiasis Mansoni: Modes of Transmission \\ and Prevention in the Perspective of Gender Differences
}

\author{
Ceci V. Noronha² ; Maurício L. Barreto² \\ Terezínha M. Silva² \& Ivete Maria Souza²
}

\begin{abstract}
NORONHA, C. V.; BARRETO, M. L; SILVA, T. M. \& SOUZA, I. M. A Popular Concept of Schistosomiasis Mansoni: Modes of Transmission and Prevention in the Perspective of Gender Differences. Cad. Saúde Públ., Rio de Janeiro, 11 (1): 106-117, Jan/Mar, 1995.
\end{abstract}

This is a study on popular ideas, beliefs and practices concerning the transmission and prevention of parasitic diseases, specifically schistosomiasis mansoni. The author explored the existence of a popular belief system within the health care system, combining elements from biomedicine and folk medicine for the understanding and management of the health/disease phenomenon. The study describes the differences in perception of morbidity and gender among the interviewwees. Finally, the study presents popular discourse on parasitic diseases and discusses diffculties with control measures. It considers the contradiction between cultural values and habits and conventional control measures, critically assessing the lack of precision in health education measures under government prevention programs.

Key words: Schistosomiasis; Social Representation; Cultural Patterns; Gender; Health Education

\section{INTRODUÇÃO}

As parasitoses constituem enfermidades de alta prevalência no Brasil, atingindo ambos os sexos, em todas as idades. As variações na prevalência da esquistossomose podem ser explicadas pelos comportamentos culturais, sobretudo aqueles que implicam exposição dos indivíduos às coleções de água próximas aos locais de moradia ou trabalho (Husting, 1970; Warren, 1973; Dalton, 1976; Souza, 1977; Jordan \& Rosenfield, 1983; Daltro, 1985; Barreto, 1987).

\footnotetext{
'Pesquisa financiada pelo Programa de Pequeña Becas para Investigações em Aspectos Sociais e Econômicos em relação às Enfermidades Tropicais, do Laboratório de Ciências Sociais - Universidade Central da Venezuela/TDR/UNDP/Banco Mundial/OMS.

${ }^{2}$ Departamento de Medicina Preventiva, Universidade Federal da Bahia. Rua Padre Feijó, 29, 42 andar, Anexo 11, Salvador, BA, 40110-170, Brasil.
}

No Brasil, o Nordeste se constitui em região endêmica para a esquistossomose mansônica, onde a doença pode ser encontrada em todos os estados. Estudos epidemiológicos realizados na Bahia registraram altos índices de prevalência de infecção pelo Schistosoma mansoni, variando de 50 a 21\% (Torres, 1980; André, 1982; Souza, 1977; Barreto, 1982, 1987; Barreto et al., 1992; Dourado et al., 1986).

O objetivo desta investigação foi analisar os discursos populares relacionados à saúde/doença, num primeiro plano, para enfocar valores, conhecimentos e práticas relativas às parasitoses. Foi nesse contexto mais geral que abordamos as experiências individuais com a infecção pelo Schistosoma mansoni e os diferenciais de morbidade por sexo.

Colocamos em evidência que nosso objeto de investigação - os modos de transmissão/prevenção da esquistossomose mansoni - oferece uma primeira dificuldade. Trata-se de objeto construí- 
do por campos especializados do saber científico: a clínica médica e a epidemiologia. Esses saberes, no entanto, foram sendo sistematizados não inteiramente desvinculados da vida social. Essa construção científica, uma vez sistematizada, não permanece como elemento de circulação exclusiva entre especialistas. As conexões entre as diferentes dimensões social, simbólica e biológica com a ocorrência da infecção/enfermidade são difundidas por indivíduos e instituições diversos, assim como passam a fazer parte da experiência dos enfermos (Minayo, 1988; Herzlich, 1991).

Young (1981), criticando os estruturalistas, afirma que o conhecimento se elabora num processo extremamente dinâmico em que se misturam conhecimentos teóricos anteriores, observações próprias sobre objetos e eventos, relatos de observações de outros atores e negociações de significados em situações de interação social. O conhecimento acerca dos eventos de doença não escapa a essas regras. Ainda, adverte o autor, não há razões para proclamar que um tipo de conhecimento seja mais autêntico do que outro, pois cada tipo está conectado para intenção e atos particulares. Cada ator produz mais de um tipo de conhecimento sobre um fato particular, e, sendo os episódios de doença fatos recorrentes, se produzirão vários tipos de saberes sobre eles, o que não assegura qualquer tipo de coerência.

\section{METODOLOGIA}

A área de estudo, Santo Antonio de Jesus, é uma cidade de porte médio, cujo crescimento populacional se deve aos fluxos migratórios. Localiza-se no Recôncavo Baiano, uma das regiões de povoamento mais antigo e receptora de escravos africanos no período colonial. Nessa região, a esquistossomose existe como endemia.

Estudamos uma subamostra da população investigada por um inquérito epidemiológico prospectivo, que acompanhou, por 12 meses, uma coorte de imigrantes recentes e de nativos (Barreto et al., 1992).

Dessa coorte, selecionamos o segmento populacional dos jovens (15 a 25 anos), por ser um dos grupos expostos à infecção pelo Schistoso- ma mansoni. Nosso universo foi constituído pelos jovens que moravam em quatro áreas da cidade, onde se concentrava maior proporção de indivíduos pobres e imigrantes. Do arquivo do inquérito epidemiológico, retiramos uma listagem com nome, endereço e condição migratória de todos os residentes das áreas selecionadas. Dos 129 indivíduos que atendiam aos critérios especificados, localizamos 65 (44 do sexo feminino e 21 do masculino).

Consideramos como nosso primeiro momento metodológico o reencontro com os 65 jovens, 12 meses após concluído o primeiro inquérito, aos quais eram formuladas quatro indagações: Você se lembra da pesquisa que fizemos? O que lembra? O que achou da pesquisa? Quer colaborar com outra pesquisa?

A partir das respostas podemos recuperar a "memória" do inquérito realizado e identificar os "nossos" informantes. Participaram do segundo momento metodológico 29 indivíduos, do sexo masculino (14) e do feminino (15), 11 imigrantes e 18 nativos. Com esse grupo realizamos entrevistas domiciliares, semi-estruturadas, acerca dos seguintes temas: saúde/doença; verminose; relação médico-paciente; lazer e relações de gênero. Desenvolvem, neste trabalho, três blocos temáticos, tratando de entrelaçar as questões de gênero com os mesmos.

A análise dos dados se processou em dois níveis: primeiro, cada entrevista foi vista de per si, classificando-se conteúdos por temas, e, em segundo lugar, foi elaborada síntese de cada tema, aproveitando-se aí todos os depoimentos, dos mais "pobres" aos mais "ricos" (Queiroz, 1983; Bardin, 1988; Brioschi \& Trigo, 1987).

A maior dificuldade metodológica foi o jogo ambíguo entre a forma e o conteúdo, na medida em que investir no conteúdo é perder um pouco a forma particular com que esse conteúdo aparece nas falas individuais. E vice-versa.

\section{A ESQUISTOSSOMOSE MANSONI EM SANTO ANTONIO DE JESUS}

Os imigrantes que se dirigem ao local do estudo procedem de áreas próximas a Santo Antonio de Jesus, o que equivale dizer que eles vêm 
de outros municípios do Recôncavo, ou seja, os imigrantes se deslocam de uma área onde a esquistossomose mansônica é endêmica para outra em igual situação.

Condizente com a situação de pobreza mais acentuada dos imigrantes, a prevalência de infecção pelo Schistosoma mansoni (dado do inquérito epidemiológico) foi mais alta nesse subgrupo. Essa prevalência não apresentou diferenças entre os sexos: $35,3 \%$ para os homens, e $35,8 \%$ para as mulheres. Essa medida da infecção se fez imediatamente após a chegada dos imigrantes à cidade (até 30 dias), o que nos assegurava de que a exposição ocorresse antes da moradia no local do estudo.

Em contraste, os nativos de Santo Antonio de Jesus apresentaram diferenças entre os sexos: $30 \%$ para os homens e $18 \%$ para as mulheres, o que significa que o grupo masculino tem, aproximadamente, duas vezes mais infecção pelo Schistosoma mansoni.

Os fatores de risco identificados como mais presentes entre os imigrantes foram: moradia em habitação sem água tratada e instalações sanitárias no local de nascimento ou de procedência; analfabetismo, desemprego, contatos com coleções de água e maior circulação por outras áreas endêmicas. Esses fatores de exposição à infecção parecem atingir o grupo feminino e masculino imigrante de modo relativamente semelhante.

As cargas parasitárias altas (acima de 500 ovos por grama de fezes) não são freqüentes na população estudada. Também não houve diferenças expressivas entre a média geométrica de ovos/grama de fezes para homens e mulheres. Os valores atingidos nessas médias foram bem próximos: 50,9 para o sexo masculino, e 43,1 para o feminino.

\section{CARACTERÍSTICAS DO GRUPO ESTUDADO}

Os entrevistados do sexo masculino trabalhavam em ocupações, tais como mecânico de autos, marceneiro, eletricista, vendedor, lavrador, estofador e encanador. No grupo feminino sete declararam trabalho remunerado, incluindo as ocupações de empregada doméstica, vendedora, manicure, artesã de flores e funcionária pública.
Em termos de escolaridade, o subgrupo feminino apresentou mais anos de educação formal do que o masculino, o que revela as diferenças de expectativas sociais em relação aos dois sexos. Todos são alfabetizados, com Primeiro Grau completo ou incompleto, mas, entre as pessoas do sexo feminino, seis cursavam o Segundo Grau. Exceto duas imigrantes, as demais ainda estudavam. No grupo masculino, 10 tiveram que optar pelo trabalho, deixando de ser estudantes.

Cinco indivíduos do grupo eram de cor branca, característico de uma região onde predominou a entrada de pessoas procedentes da África, durante todo o período colonial.

Apenas três dos entrevistados/entrevistadas não moravam com os pais. Duas entrevistadas eram empregadas domésticas e habitavam a casa dos patrões, e um dos entrevistados havia constituído sua própria família, vivendo independentemente.

As quatro áreas residenciais escolhidas para estudo se caracterizam pela presença de esgotos correndo a céu aberto, córregos passando pelos quintais e áreas alagadiças em determinada época do ano. Essa situação denota a precariedade do saneamento básico na cidade.

\section{AS CONCEPÇÕES DE SAÚDE/DOENÇA: DIFERENÇAS POR SEXO E GÊNERO}

Estar doente significa para o grupo: ficar de cama; não fazer nada e/ou fazer coisas pelas mãos dos outros. As causas podem ser provenientes da exposição do corpo e da mente às condições climáticas (calor, frio, umidade, chuvas, ventos), o que pode ocasionar uma série de agravos à saúde; às "preocupações" com dinheiro, que produzem "nervo" e "pressão alta", e dor de cabeça; ao "destino" de cada um, que inclui o sofrimento e as doenças como males inevitáveis; às condições sociais e econômicas, que não permitem boa alimentação e adequada recuperação das "forças".

Quanto às representações sobre morbidade e sexo, a maioria acredita que o sexo feminino adoece mais, segundo observações no seu grupo familiar ou de amizade. $\mathrm{O}$ argumento é que as mulheres são mais "fracas" ou "frágeis". No entanto, com relação às verminoses, a idéia é exa- 
tamente oposta. É dito que o sexo masculino está mais exposto, porque os meninos/homens são mais destemidos, trabalham mais e têm mais liberdade para andar no mato, na lama e em outros locais que implicam riscos para a saúde.

As razões pelas quais as mulheres se configuram como o sexo que adoece mais estão ligadas, em parte, ao aparelho reprodutor, com ênfase para o ciclo menstrual, que aparece como problema de saúde. Outro conjunto de entrevistados disse que as mulheres gostam mais de falar sobre sinais e sintomas de doença, apresentando também o comportamento de doente com mais facilidade. Mechanic (1978) é um dos pesquisadores que enfatizam o peso dos componentes sociais e culturais na configuração das diferenças de morbidade por sexo, distinguindo sua importância nos relatos sobre doença e nos comportamentos de doente.

Para estabelecer essas comparações entre sexo e enfermidades, a mãe do depoente é, freqüentemente, tomada como centro de observação. É lógico que, aos olhos dos jovens, os mais idosos representarão sempre um grupo com mais queixas de saúde, independentemente do sexo.

O depoimento mais ilustrativo foi o dessa jovem:

"Minha mãe é problema de vesícula, dores nas costas, dores nas pernas, na cabeça, nunca vi! Parece um poço de dores!" (Elisângela)

A mãe é tomada como objeto de observação, porque é maior a convivência, no domicílio, entre mães e filhas/filhos. Isso prolonga o tempo de observação sobre o comportamento e discurso materno face às enfermidades, o que não encontra correspondência na consideração do pai. Há, portanto, bias na comparação. Mechanic (1978) levantou críticas conceituais e metodológicas aos estudos dos diferenciais de morbidade por sexo, indicando o momento da coleta de dados como um dos principais problemas. $\mathrm{O}$ uso do proxy respondente constitui apenas uma das formas de introduzir bias nessas comparações.

Outras entrevistadas não fizeram qualquer tipo de ponderação e afirmaram que as amigas ou as mulheres de sua família adoeciam mais. Acrescentavam, mesmo, uma expressão muito enfática: "são sempre as mulheres!" E essa associação entre mulher e doença pode ir além, sendo tomada como elemento exemplar das dificuldades que o sexo feminino enfrenta na vida, considerando tanto a condição biológica quanto social.

Os homens se referiram pouco ao desgaste masculino. no trabalho e ao surgimento de enfermidades. Um dos raros depoentes sobre essa questão se expressou da seguinte forma:

\section{"É, o homem é difícil de ficar doente, mas se acaba no trabalho, pega peso, bebe mais bebidas alcóolicas e não liga de ir ao médico efazer exames". (Enok)}

O depoimento faz uma alusão ao homem como o principal prover na dinâmica da reprodução do grupo famliar. Ainda que esse papel passe, no momento atual, por muitas mudanças, as representações sociais tendem a mantê-lo. Outras características do universo masculino são colocadas, tais como o uso de bebidas alcóolicas e o pouco interesse pela procura dos serviços de saúde.

Estudar os papéis sociais atribuídos a homens e mulheres implica distinguir os conceitos de sexo e gênero. O primeiro é tomado como noção relativa às características biológicas dos indivíduos; o gênero constitui construção social e cultural acerca dessas diferenças biológicas (Barbieri, 1993).

Observamos que o discurso de um gênero sobre o outro é formulado de forma hesitante, e cheia de reticências, acompanhado de certo constrangimento, que se revela no riso freqüente ou nas respostas evasivas.

Para os jovens entrevistados uma série de categorias negativas definem o que é ser mulher: sofrimento, dificuldades, culpa, luta, repressão, complicação, discriminação e dependência.

Em contraste, os homens são definidos por qualificativos positivos pela maioria dos entrevistados. Eles são identificados, basicamente, pela condição de mais liberdade face às mulheres.

Nesse contexto, em que predominam valores tradicionais que colocam as mulheres em condi- 
ção de subordinação, os entrevistados tenderam a associar maior freqüência de verminoses aos meninos e homens. Esse fato, na concepção deles, tem relação com as "virtudes" masculinas. Vejamos alguns argumentos:

"Os meninos são mais danados, andam mais descalços. Os meninos não ligam, tem meses de chuva que quando chove os meninos gostam de estar naquela poça suja de lama. Geralmente as meninas, as mães não deixam, ficam chamando: não vá para a rua! E os meninos, eles não ligam muito. Assim que eu falo que a mãe... a menina, acho que desde pequena a mulher tem aquela coisa, homens pode, mulher não pode. Então os meninos andam mais por aí; os pais não ligam muito. Eles ligam, mas não é muito”. (Renilda)

Fica evidente a associação entre verminose e ambiente sujo, bem como o modo em que a educação do menino e da menina diferem em função das construções simbólicas relacionadas a um sexo e outro. São essas diferenciações elaboradas na vida social que constituem a matéria prima do conceito de gênero.

\section{"Os meninos pegam mais verminose, porque} são mais porcos, imundos (risos)”.

(M. Conceição)

Na relação estabelecida entre os meninos e as verminoses, um aspecto que denota negatividade é aliar comportamentos não higiênicos ao sexo masculino, opinião comum a ambos os sexos.

\section{"Os meninos pegam mais verminose, porque} tomam muito mais banho de rio, sai muito". (Sidnei)

Comportamentos mais livres e desafiadores são parte das expectativas que se têm acerca do sexo masculino. O banho de rio pode ser um exemplo da intrepidez masculina ou de maior disponibilidade de tempo para o lazer e o ócio.

Uma parte minoritária dos/das entrevistados/ entrevistadas assumiu posição diferente da dominante ao afirmar que não há diferenças entre o número de pessoas com verminose num sexo ou nou- tro. Eles/elas se referiram às condições mais gerais de higiene e alimentação como os fatores determinantes das verminoses, não apontando nenhum comportamento atribuível a um sexo ou outro para explicar as razões da infecção.

\section{AS PARASITOSES E A ESQUISTOSSOMOSE MANSÔNICA}

Considerando o conjunto das parasitoses, podemos afirmar que muitas são comuns à experiência dos entrevistados, ocorrendo, até mesmo, mais de uma vez.

"Já tive áscaris, depois ameba, deu áscaris... Não sei como peguei, acho que... porque, quando eu era menor, eu acho que não tinha lá essas águas encanadas não. Vinha mais água de fontes, de cisternas, eu bebia dessas águas': (Elivonete)

Foi observada uma certa hesitação ao falar sobre doença, discurso no qual é freqüente o uso da expressão "não sei". A hesitação pode ser indicativa de que o sujeito não se sente plenamente autorizado para falar sobre isso, ficando assim reiterado o monopólio do médico sobre o assunto.

"Deu umas vermes mas ficou até de eu usar uns remédios mas eu não usei não. Sei lá, não usei por facilitação. Foi uma verme simples. A verme estraga muito a pessoa, estraga muito o intestino por dentro, estraga muito a pessoa, de qualquer forma ela estraga, não sei explicar como, mas sei que ela estraga. Não tomei o remédio porque, às vezes, é facilitação, eu queria 'tomar umas, queria tomar uma pinga', um 'negócio' e, eu achava que ía... Já tive verme antes, tomei remédio, depois tomei purgante, limonada. Purgante para limpar o intestino. O remédio já tinha feito efeito, eu tomei a limonada para limpar o intestino". (Sidney)

Podemos constatar nas declarações que é difícil separar o discurso da transmissão e da prevenção. O próprio relato individual da experiência com o problema emerge entrelaçando a causação, as medidas preventivas e o tratamen- 
to. Isso coloca em destaque que a distinção desses aspectos é algo próprio ao modelo da biomedicina apenas.

Os jovens do sexo masculino fizeram, em diferentes situações, referência ao uso de bebidas alcoólicas, seja porque elas representam risco para a manutenção do corpo saudável, seja por seus efeitos negativos, quando ocorre sua ingestão simultaneamente aos medicamentos industrializados. A idéia de protelar o medicamento para poder consumir álcool se articula com a imagem do jovem como pessoa imediatista, que gosta de "curtir a vida", conforme definição do próprio grupo. O uso de "purgantes" como estratégia para a limpeza do corpo demonstra como ainda se complementam as prescrições médicas com o modelo popular de tratamento das enfermidades.

Do conhecimento do grupo salientamos também a existência de uma classificação dos vermes em "comuns" ou "simples" e vermes "perigosos". O Schistosoma mansoni se encontra na classe dos vermes "perigos".

A denominação mais utilizada por eles/elas é "Schistosoma", o que em si revela certa aproximação do conhecimento do grupo com as explicações da biomedicina. Compreensível também por se tratar de grupo alfabetizado.

"Tive Schistosoma, eu tomava banho de rio quando cheguei aqui em Santo Antonio de Jesus. Essa verme tem cura porque tem remédio... Eu achava que era só tomar o remédio uma vez e ficava bom. Aí tomei a primeira vez, aí era para eu voltar dentro de 45 dias ao médico. Aí, 45 dias eu não voltei, eu mesmo comprei mais dois remédios, três remédios e depois mais três, mas não voltei ao médico. Por quê? Porque assim, para ir no médico, passar exame, é acordar de madrugada para ir no escuro. É muito ruim ir até lá (risos)”. (Elias)

Há um paradoxo no discurso dos jovens, que é aparente, porque, se o Schistosoma mansoni é considerado "perigoso" entre as verminoses, esse risco, no entanto, é relativizado pela experiência com outras doenças. Ademais, a crença na cura para a infecção esquistossomótica está bem sedimentada no grupo, e, sobretudo, a infecção não é considerada algo que coloque a vida sob ameaça de morte.
As parasitoses constituem um tipo de agravo à saúde já experimentado por todos os informantes, seja na infância ou no presente, alguns casos se destacando pela severidade:

"Já teve época que tive sete tipos de vermes, no meio estava o Schistosoma. Só porque eu tomava banho de rio. Como descobri? Fui parar em Salvador, fui fazer exames lá, porque em Amargosa me disseram que eu tava com problema no rim. Queriam me operar, aí eu fui para Salvador. Os médicos de lá falaram. Para você ver, tava atacando meu fígado, já tava todo ruído, aí eu tomei uns remédios, foi que foi reconstituindo ". (M. Conceição)

Encontramos um caso de óbito no grupo familiar provocado pelo Schistosoma mansoni, fato enfatizado pela entrevistada como um acontecimento do passado. Segue o relato:

\section{"Minha avó foi o problema do Schistosoma que é ... mas eu nem tinha nascido ainda, ela morreu. Aí foi por causa de tratamento, porque ela morava na roça e, aí; acho que logo de início não trataram. Não teve jeito. Como ela pegou? Sei sim, água de rio mesmo porque só andava descalça, andava na fonte, acho que pescava também, eu não sei direito, nem tinha nascido. Acho que foi falta de assistência, se fosse hoje em dia, né? Ela iria no médico, o médico já descobria que era schistosoma, né? De início, tomaria remédio, faria o tratamento direitinho, acho que... estaria aí, até hoje. Descobriu depois, quando cresceu a barriga d'água, aí, minha mãe levou no médico... Aí não tinha mais jeito ". (Rosângela)}

Indagados os entrevistados quanto à vida dos vermes no organismo humano, a maioria concorda que eles podem sobreviver por muito tempo e, sobretudo, se reproduzir:

"Acho que fica muito tempo até... se não tomar remédio pra matar, eles ficam direto. Fora do corpo morre, porque não tem nada para se alimentar”. (M. Conceição)

A questão dá sobrevivência do agente etiológico dentro/fora do organismo humano é 
elemento-chave para que o ciclo de transmissão do Schistosoma mansoni venha a fazer sentido para os indivíduos leigos. As diferenças entre a concepção popular e a da biomedicina estão centradas nesse ponto, em que a dimensão dos alimentos para os parasitos aparece como a mais importante.

"Vive, geralmente, assim vai depender do verme, né? E. causa danos, tanto vivo quanto morto, o Schistosoma mesmo morto ele causa danos ao organismo”. (José)

Interessante constatar mais uma idéia acerca do perigo representado pelo Schistosoma mansoni que, apesar de morto, dentro do organismo, continua a ser um agravo à saúde.

"Acho que fica, acho que se deixar é arriscado até matar, porque foi juntando, ali vai criando, produzindo”. (Denilza)

A entrevistada faz referência à capacidade reprodutiva do agente etiológico que, tomando o organismo humano como habitat, pode proliferar, indefinidamente, colocando a vida do indivíduo parasitado sob risco de morte. Observação rara entre as pessoas do grupo.

Foi minoritária a opinião contrária, argumentando que, se a pessoa está muito cheia de vermes, esses tendem a ser expelidos pelo organismo, independentemente de medicamento. Um informante lembrou de relatos dos mais idosos que afirmam já ter visto pessoas morrendo e colocando vermes pela boca.

A vida dos vermes no ambiente, após terem sido expelidos do organismo humano, é colocada em dúvida pelo grupo. A maioria está convencida de que os vermes, ao serem expulsos do corpo humano, morrem.

\section{"A verme fora do corpo ela morre, quando não tem fossa para cair, ela não vive porque não tem alimento para ficar, mas assim, à toa, ela morre porque não acha lugar para se espalhar". (Denilza)}

A percepção de que dispor, ou não dispor, de alimentos é fundamental para a sobrevivência do agente etiológico, constituindo o corpo humano o locus por excelência para esses seres, reforça a crença do grupo de que, na natureza, os parasitos morrem. Helman (1986), estudando as concepções sobre os germes dos habitantes do subúrbio de Londres, descreve algo semelhante. Na visão da população, os germes não teriam existência na natureza, portanto, sobrevivem única e exclusivamente, nas pessoas ou entre as pessoas.

\section{"Para mim ela morre ou, então, os bichos comem". (Adriana)}

A compreensão de que há uma cadeia alimentar e que os parasitos podem fazer parte dela se expressa nesta fala:

\section{"Fora do corpo eles não são mais nada, ali eles não tão se alimentando, né, da nossa matéria. Ali eles morrem". (Enok)}

Encontramos aí a idéia básica do grupo acerca do que é um ser parasita, aquele se alimenta de outro. Uma noção que é, por vezes, transferível do domínio da biologia para a vida social, quando se nomeia, assim, indivíduos que não gostam de trabalhar e sobrevivem à custa dos demais.

Apenas uma entrevistada teve opinião divergente quanto à morte do agente etiológico no ambiente. Ela declarou:

"Vivem, vivem algum tempo sim, quer dizer, o Schistosoma no rio, no caramujo, deitado no caramujo, né? Aí se a pessoa entrar em contato com a água se contamina. Agora no chão também vivem, mas não sei quanto tempo porque sempre sai um, vem outro, sempre está cheio de sujeira, né? Sempre no chão está poluido, onde a gente passa está poluído”. (Rosângela)

Os informantes, de modo generalizado, demonstraram conhecer o processo de transmissão das verminoses. Eles/elas se reportaram às suas fontes de informação (professores, médicos etc.) e falaram algo bem próximo do modelo explicativo da biomedicina. Eles/elas identificam que os hábitos de higiene pessoal, o contato com as coleções de águas, a ingestão de determinados alimentos, a forma de prepará-los e o consumo de água de má qualidade estão associados às verminoses. Seguem alguns exemplos: 
“Ah! É através dos pés, através de banho de rio também e, principalmente, descalço, né? Entra assim pelo pé, a gente não sente, a gente acha difícil mas entra sim. Nos estudos de ciências a gente observa bem o desenho". (Gersonita)

Os orifícios humanos, principalmente a boca, são facilmente reconhecidos como porta de entrada para muitos agravos à saúde; o difícil é admitir que a pele também possa assumir esse papel.

"Tem uns micróbios pequenos que entra na água dentro do caramujo, aí, pronto! Aí ele entra no corpo da gente, aí causa ovos. Os ovos nasce nas fezes aí, pronto, vai nascendo, vai gerando. Ele entra no corpo pelo caramujo, sai pelas larvas, entra no corpo da gente, vai pequenininho entra, aí, pronto. Depois que tá no bucho vai crescendo, recebendo alimentação aí de nós, já vai comida para dois (risos). No corpo vive até quando a pessoa não cuidar dele, não tomar remédio pra matar, mas, quando a pessoa toma remédio, liquida logo com ele!". (Elias)

A reprodução mais aproximada do modelo da biomedicina para a transmissão da esquistossomose aparece no depoimento, incluindo com o uso do vocábulo "micróbio" tomado de empréstimo do discurso científico. Indagado quanto à diferença entre verme e micróbio, o entrevistado declarou que é "tudo quase igual": o verme pode ser micróbio e este pode vir a ser verme.

A indagação relativa à aparência dos vermes fez emergir o sentimento de repulsa dos indivíduos aos agentes etiológicos em estudo. Uma série de termos pejorativos foram usados para criar uma imagem acerca dos vermes: "feínhas", "nojentas", "horríveis", "brancos", "tristes" e "esquisitos".

As idéias sobre prevenção são também reveladoras do intenso processo de medicalização da população. A título de exemplo:

"É estar sempre no médico, evitar banho de rio, principalmente, com esse negócio de cólera, né? Não tomar banho de rio, se prevenir bem”. (Elisângela)
A crença na medicina de base tecnológica surge com força nas declarações dos jovens, talvez por ser esse segmento populacional mais influenciável aos apelos da "ciência", do "moderno" e do "progresso", tomados aqui como categorias centrais da nossa sociedade.

"Pessoa sadia é que não tem verminose, tem bastante higiene, que anda limpo, não anda descalça, come comidas bem tratadas e vai, constantemente ao médico, né? Fazem exames de fezes e urina periodicamente, tomar remédio. Pessoa sadia é assim, que vai sempre ao médico, fazem consultas constantes porque a pessoa nunca sabe que tá sadio, né?

Sempre tem que tá em contato com o médico para saber, para estar informado... porque, às vezes, ela está se sentindo bem, bem, bem mesmo e tem coisa, sei lá... tem problema de saúde que a gente não sente logo não, fica sempre, se a gente pensar que tá numa boa, depois que acontece? Cai, morre, nem sabe de que morreu". (Édson)

Esta é mais uma forma de reiterar o monopólio da biomedicina sobre os fenômenos da doença: o sujeito não mais pode falar ou reconhecer a sua doença sem recorrer à instância legitimadora representada pelos médicos. É também imprescindível recorrer aos exames laboratoriais, de acordo com esse entrevistado, porque há situações em que o indivíduo não sente sintoma algum, mas já se encontra infectado, o que pode ocorrer com a infecção em estudo.

Na questão do tratamento, convém salientar a ênfase atribuída ao poder de cura dos medicamentos industrializados, descritos por eles/elas como tão eficazes, que se pode até "facilitar" nas práticas preventivas. Alguns poucos ainda admitem aliar esses medicamentos industrializados aos remédios caseiros.

Desse modo, notamos que nenhum dos informantes fez referência aos vendedores de ervas e outros "medicamentos" que costumam expôr seus produtos nas feiras locais. Nós os observamos por serem eles agentes alternativos de cura e formuladores de um discurso especial sobre saúde/doença.

O discurso mais contundente era o de um homem branco, de olhos verdes, que anunciava seus 
produtos com demonstrações sobre a ação dos vermes no organismo. Ele usava as ilustrações de um livro de Ciências para o Primeiro Grau. O refrão da sua propaganda era: "porque verme, meu irmão, todo mundo tem!”

Os efeitos devastadores dos vermes podiam ser constatados em uma foto de criança desnutrida. A platéia era formada por homens, mulheres e crianças. $\mathrm{O}$ vendedor dramatizava ao máximo: "a verminose mata, cega e leva à loucura!" Perguntamos se conhecia o Schistoso$m a$, ele recorreu, mais uma vez, ao livro para discorrer sobre o ciclo de transmissão, acrescentando: "ele tem uma ponta fina e ataca o fígado". O produto que ele nos recomendou para todos os vermes não tinha rótulo, endereço ou nome do fabricante.

Outros vendedores e ervateiros declararam que não tinham remédios para vermes e recomendavam os medicamentos mais conhecidos entre os vendidos em farmácia. Alguns recomendavam alguma raiz para acompanhar, sob a forma de chá, o medicamento industrializado.

A importância de um setor folk de saúde (ao qual os ervateirós e outros agentes estão vinculados) para o conhecimento e tratamento das verminoses parece restrita, no grupo jovem estudado. As escassas referências ao uso de chás medicinais eram atribuídas à ação ou crença dos membros mais velhos da família.

Por outro lado, é ambivalente a relação dos jovens com os profissionais de saúde. Apesar da ênfase na necessidade de consultar um médico para qualquer alteração do estado vital, incluindo a prevenção das verminoses, de forma mais sutil era revelado que essas declarações nem sempre eram seguidas por eles próprios.

\section{COMPORTAMENTO PREVENTIVO: DIFICULDADES}

A maioria dos entrevistados/entrevistadas, após narrar o que sabia sobre prevenção, afirmava não colocar em prática tais comportamentos. Muitos riam constrangidos e tentavam uma autocrítica para seguir fazendo tudo como faziam antes.

O hábito de andar sem calçados foi identificado como o mais difícil de ser evitado. Outras dificuldades apontadas foram relativas à higie- ne pessoal: a preguiça de lavar as mãos sempre que necessário; a pouca disposição para lavar bem as frutas, a relutância em abandonar o prazer de comer carnes malpassadas ou pouco cozidas ou evitar o banho de rio, açudes, lagoas após jogar uma partida de futebol.

Mello et al. (1988) chegou a resultados semelhantes em uma investigação com um grupo populacional do interior de São Paulo. Rozemberg (1994), estudando as representações sociais acerca da esquistossomose em uma localidade rural do Espirito Santo, assinala que há um nível de "informações" razoável entre os entrevistados, embora isso não tenha relação direta com a incorporação de hábitos preventivos.

Alguns autores analisam que o processo de busca da saúde comporta relações extremamente complexas dos indivíduos e dos grupos sociais frente às enfermidades. Os sistemas médicos atuam nesse processo com certas simplificações ou esquemas padronizados (Kleinman, 1978; Pedersen, 1991).

\section{ATIVIDADES DE LAZER}

As oportunidades de lazer dos jovens incluem atividades que têm implicações para a transmissão da esquistossomose. A primeira é o banho de rio, açude ou lagoa, referido com maior freqüência pelo grupo masculino. A segunda é o contato com áreas rurais nas proximidades da cidade.

Os entrevistados (exceto quatro pessoas) costumam sair de Santo Antonio de Jesus para visitar amigos ou parentes em outras localidades. Para qualquer programa de controle da esquistossomose a circulação dos indivíduos é considerada dado importante, podendo significar exposição à infecção.

Para o grupo feminino, uma dimensão a considerar é que as mulheres estão mais protegidas da exposição às coleções de água, no espaço urbano de Santo Antonio de Jesus, por conta das idéias e valores morais. Não parece apropriado ao grupo que adolescentes do sexo feminino se exponham, mostrando o corpo nos banhos de açudes ou em córregos.

Para as mulheres, as chances de contato com água, por motivo de lazer, são mais restritas. Assim, podemos sugerir que os valores morais 
do grupo social estudado têm participação específica, difícil de precisar, nos diferenciais de infecção pelo Schistosoma mansoni.

\section{CONCLUSÕES}

$\mathrm{Na}$ percepção do grupo estudado o mais dificil é compreender os aspectos "invisíveis" do ciclo de transmissão da esquistossomose, ou seja, a existência de seres microscópicos que contribuem para completar o ciclo. A crença do grupo é que, fora do corpo humano, os vermes morrem, ficando, assim, uma lacuna quanto às relações entre: agente etiológico ambiente - homem. No entanto, há um conhecimento partilhado pelo grupo sobre a infecção pelo Schistosoma mansoni, reiterado pela experiência dos indivíduos que habitam uma região endêmica e pelos encontros terapêuticos da população com profissionais de saúde. As ações de educação para a saúde devem, portanto, enfatizar os principais pontos de divergências entre o conhecimento científico e o popular.

Rozemberg (1994), analisando o modo como o conhecimento popular acerca da esquistossomose se elabora, descreveu um processo complexo ém que a passagem do desconhecido ao conhecido se faz mediante a fusão de informações do modelo biomédico, da observação direta dos indivíduos sobre as atividades desenvolvidas pela Fundação Nacional de Saúde, as próprias experiências com a infecção/doença e as possíveis lacunas sendo preenchidas por categorias do imaginário.

Acreditamos que é essa complexidade dos processos cognitivos que se traduz em ambiguidades no uso do conceito das representações sociais, freqüentemente definidas como idéias e valores aderidos a ações específicas. Para entender o comportamento de alguém é necessário entender, primeiro, o sentido desse comportamento para quem é observado. Os hábitos de higiene, relacionados ao controle das verminoses, estão calcados em noções bem elementares definidas pela cultura acerca do limpo e do sujo. Isso equivale a dizer que tanto os indivíduos como as coletividades participam dessas elaborações. Também devemos atentar para o fato de que os indivíduos reproduzem as ações cotidianas sem muitos questionementos, uma vez que se trata de internalizações com as quais se sentem familiarizados desde o nascimento. No caso da esquistossomose, pode parecer intrigante que um hábito higiênico (tomar banho em rios) possa significar exposição a uma enfermidade.

Herzlich (1991), ao problematizar a importância dos estudos relativos às representações sociais, no campo da saúde, assinalou que em um período de tempo relativamente curto e no contexto das sociedades industriais, as representações tendem a ter grande estabilidade. Dessa forma, é possível encontrar resultados bem semelhantes no estudo das representações entre grupos populacionais diferenciados, em um mesmo período histórico e no contexto de uma mesma cultura.

Explorar os significados de uma enfermidade para um determinado grupo populacional implica focalizar, primeiro, a relação da problemática da saúde/doença na configuração dos valores centrais da sociedade ocidental comtenporânea. Certamente, nesse tipo de sociedade, a saúde se tornou um bem simbólico inquestionável. Podem divergir as concepções de doença e dos modos de tratá-las, mas a saúde permanece como um valor cuja positividade é almejada por todas as camadas sociais, etnias ou gerações. Nesse plano, a doença, como o oposto da saúde, pode ser reificada como experiência individual e coletiva.

O controle da esquistossomose é concebido para intervir sobre a população e o meio ambiente. No que concerne à população, temos o tratamento dos infectados e as ações educativas. As atividades de educação implicando diretamente mudanças de hábitos ou prescrições comportamentais devem-se conformar, levando em conta conhecimentos, valores e práticas dos segmentos populares. No entanto, parece surpreendente que as ações educativas apareçam nos programas de intervenção de modo vago e conceitualmente impreciso.

Em todas as áreas (endêmicas, com potencial endêmico ou indenes), as atividades de educação não parecem encontrar espaço e fundamentação teórica apropriados. O enfoque comportamental e individualista se revela pobre para fazer cumprir as expectativas de levar a população a interromper a cadeia de transmissão (Silveira, 1989). 


\section{RESUMO}

NORONHA, C. V.; BARRETO, M. L.; SILVA, T. M. \& SOUZA, I. M. Uma Concepção Popular Sobre a Esquistossomose Mansônica: Os Modos de Transmissão e Prevenção na Perspectiva de Gênero. Cad. Saúde Públ., Rio de Janeiro, 11 (1): 106-117, jan/mar, 1995.

Estudo sobre as concepções e práticas populares acerca da transmissão e prevenção das parasitoses, com ênfase para a esquistossomose mansônica. Explora a existência de um sistema popular de cuidados de saúde que mescla elementos da biomedicina e da medicina tradicional como forma de compreender e manejar os fenômenos de saúde/doença. Descreve as diferenças entre morbidade e sexo/gênero na concepção dos sujeitos entrevistados. Apresenta o discurso popular sobre as parasitoses, discutindo as dificuldades das ações de controle. Considera as contradições entre hábitos e valores culturais e as medidas de controle conhecidas, criticando a imprecisão das ações educativas nos programas oficiais de intervenção.

Palavras-Chave: Esquistossomose; Representação Social; Padrões Culturais; Gênero; Educação em Saúde

\section{REFERÊNCIAS BIBLIOGRÁFICAS}

ANDRÉ, S. B., 1982. Aspectos Sócio-Culturais da Esquistososmose Mansoni no Município de Sapeaçu - Bahia. Tese de Mestrado, Salvador: Departamento de Medicina Preventiva, Universidade Federal da Bahia.

BARDIN, L., 1988. Análise de Conteúdo. Lisboa: Edições 70.

BARBIERI, T., 1991. Sobre a Categoria Género: una Introducción Teórico-Metodológica. Recife: Fundação Carlos Chagas. (Mimeo.)

BARRETO, M. L., 1982. Esquistossomose Mansônica: Distribuição da Doença e Organização do Espaço. Tese de Mestrado, Salvador: Departamento de Medicina Preventiva, Universidade Federal da Bahia.

1987. Epidemiology of Urban Schistossomiasis mansoni in Northeast Brazil: A Case Study in Santo Antonio de Jesus. Tese de Doutorado, London: London School of Hygiene and Tropical Medicine.
BARRETO, M. L.; NORONHA, C. V.; ANDRADE, A. E. O.; SANTOS, R. M.; MARTINEZ, M. O. \& SAMPAIO, J. S., 1992. Migration and Spred of $S$. mansoni Infection in an Urban Place in Northeast Brazil. Final Report to TDR/OMS, Salvador: Departamento de Medicina Preventiva, Universidade Federal da Bahia. (Mimeo.)

BRIOSCHI, L. R. \& TRIGO, M. M. B., 1987. Relatos de vida em ciências sociais: considerações metodológicas. Ciência e Cultura, 39: 631-637.

DALTON, P. R., 1976. A socioecological approach to the controi of Schistosoma mansoni in St. Lucia. Bulletin of the World Health Organization, 54: 587-595.

DALTRO, M. E. P., 1985. Fatores Culturais na Transmissão da Esquistossomose Mansônica. Tese de Mestrado, Salvador: Departamento de Medicina Preventiva, Universidade Federal da Bahia.

DOURADO, M. I. C.; NORONHA, C. V. \& LOUREITO, S., 1986. Esquistossomose mansoni: um Estudo de Fatores de Risco em uma Área do Recôncavo Baiano. Relatório de Pesquisa, Salvador: Departamento de Medicina Preventiva da Universidade Federal da Bahia. (Mimeo.)

HELMAN, C., 1986. Feed a cold, starve a fever: folk models of infection in an english suburban community, and their relation to medical treatment. In: Concepts of Health, Illness and Disease. A Comparative Perspective (C. Currier \& M. Stacey, ed), pp. 211-231, New York: Berg Publishers.

HERZLICH, C. A., 1991. A problemática da representação social e sua utilidade no campo da doença. Physis, 1: 23-25.

HUSTING, E. L., 1970. Sociological patterns and their influence on the transmission of bilharziasis. Central African Journal of Medicine, 16: 0510.

JORDAN, P. \& ROSENFIELD, P., 1983. Schistosomiasis control: past, present, future. Annual Review of Public Health, 4: 311-334.

KLEINMAN, A., 1978. Concept and model for the comparison of medical systems as cultural systems. Social Science \& Medicine, 12: 85-93.

MELLO, E.; PRIPAS, S.; FUCI, M.; SANTORO, M. C. \& PEDRAZZANI, E. S., 1988. Helmintoses intestinais. (I) Conhecimentos, atitudes e percepções da população. Revista de Saúde Pública, 22: 140-149.

MECHANIC, D., 1978. Sex, ilness, ilness behavior and the uses of health services. Social Science $d c$ Medicine, 12B: 207-214.

MINAYO, M. C. S., 1988. Saúde-doença: uma concepção popular da etiologia. Cadernos de Saúde Pública, 4: 363-381. 
PEDERSEN, D., 1991. Curandeiros, divindades, santos y doctores: elementos para el analisis de los sistemas medicos. In: America en Construccion (C. Pinszon, ed.), pp. 292-317, Amsterdam: ICAN, Universidad de Amsterdam.

QUEIROZ, M. I. P., 1983. Variações sobre a Técnica de Gravador no Registro da Informação Viva. São Paulo: FFLCH/USP. (Caderno Ceru, 4)

ROSEMBERG, B., 1994. Representação social de eventos somáticos ligados à esquistossomose. Cadernos de Saúde Pública, 10: 30-46.

SILVEIRA, A. C., 1989. Controle da esquistossomose no Brasil. Memórias do Instituto Osvaldo Cruz, 84 (supl. 1): 91-103.

SOUZA, S. L., 1977. Schistosomiasis mansoni in Children: an Epidemiologic Study of Water Exposure Using Path Analysis. Tese de Doutorado, Houston: Texas School of Public Health.
TORRES, O., 1980. Esquistossomose Mansônica no Vale do Paraguaçu - Bahia. Tese de Mestrado, Salvador: Departamento de Medicina Preventiva, Universidade Federal da Bahia.

WARREN, K. S., 1973. Regulation of prevalence and intensity of Schistosomiasis in man: imunology or ecology? Journal of lnfections Diseases, 127: 595-609.

YOUNG, A., 1981. The creation of medical knowledge: some problems in interpretation. Social Science \& Medicine, 15B: 379-386. 